\title{
Retention of Probase Hot Versus the Conventional Heat- Cured Acrylic Resin Denture Bases
}

\author{
Noha A El Sharkawi ${ }^{1}$, Ibrahim M Hamouda ${ }^{2,3 *}$, Amira M Gomaa ${ }^{4}$ and Ali H El Shkouki ${ }^{5}$ \\ ${ }^{1}$ Department of Prosthetic Dentistry, Mansoura University, Egypt \\ ${ }^{2}$ Department of Dental Biomaterials, Mansoura University, Egypt \\ ${ }^{3}$ Department of Head of Restorative Dentistry, Faculty of Dentistry, Umm Alqura University, KSA
}

${ }^{4}$ Department of Prosthetic Dentistry, Mansoura University, Egyptz

${ }^{5}$ Department of Prosthetic Dentistry, Mansoura University, Egypt

Received: August 14, 2017; Published: September 06, 2017

*Corresponding author: Ibrahim M Hamouda, Department of Dental Biomaterials, Faculty of Dentistry, Mansoura University, Mansoura, Egypt, Email: imh100@hotmail.com

\begin{abstract}
This study compared the retention of proBase hot versus a conventional heat-cured acrylic resin denture bases. Two completely edentulous patients of U-shaped and V-shaped palatine vault. Primary and secondary impressions of the maxillary arch were done to produce two master casts. Each master cast was duplicated into twenty-one stone casts using duplicating hydrocolloid. Standardized maxillary waxed denture bases were produced by duplication using silicone impression material. Twenty-one standardized denture bases for each tested (U- and V-shaped) maxillary arches were obtained. Stainless steel wire loops were placed at a vertical direction in the marked center of each waxed denture base for dislodging each acrylic denture base from its basal seat to measure its retention. Fourteen waxed denture bases constructed for each of U- and V-shaped palatal vault were processed into conventional heat cured acrylic, while the other seven waxed denture bases were processed into ProBase Hot denture bases as recommended by the manufacturer. A digital force meter was used for retention measurement. The results indicated a significant differences between the tested materials and the two arch forms. ProBase Hot showed the highest retention than that of the conventional acrylic resin (Acrostone) either long- curing or short-curing method.
\end{abstract}

Keywords: Denture Base Materials; Probase Hot; Conventional Acrylic Resin; Long-Curing Method and Short- Curing Method

\section{Introduction}

Since the mid-1940s, the majority of denture bases have been fabricated using polymethyl methacrylate resins. Heat-activated materials are used in the fabrication of nearly all denture bases [1]. It was excellent esthetic properties, low water sorption, low solubility and adequate strength [2]. In recent years many attempts have been made to improve dentures by special methods of processing, Such as light activated resin, microwave activated resin, and vacuum-plus-pressure low-temperature polymerization techniques [3]. Other polymers developed include vinyl acrylic, polystyrene, epoxy, nylon, vinyl styrene, polycarbonate, polysulfideunsaturated polyester, polyurethane, polyvinylacetate- ethelene, hydrophilic polyacrylate, silicones, rubber- reinforced acrylics, and butadiene-reinforced acrylic [2].

Unfortunately, all available resins used in dentistry undergo shrinkage during processing. Ill fit denture was evident as a result of shrinkage of denture base. The posterior border of the denture base shows the greatest amount of processing shrinkage. The greater the curvature of the tissue at the posterior palatal region, the greater its distortion. Studies revealed non-uniform discrepancy pattern between the denture base and cast. The greater discrepancy occurred at the mid-palatal region of the posterior border in the area of posterior palatal seal. Discrepancies in this area will most certainly have a negative effect on the retention of a denture base $[4,5]$.

Adaptation of denture to the supporting structures improves the retention of the denture [3]. The adaptation is deteriorated by denture processing, cooling of the flasks, and during finishing and polishing. All these processes result in war page of the denture base [1]. All available resins used in dentistry undergo shrinkage during processing. Ill fit denture was evident as a result of shrinkage of denture base [3]. Enerally satisfactory processing temperature for the heat curing acrylic resin is between $71^{-77^{\circ}} \mathrm{C}$ regarding its 
dimensional stability. A satisfactory processing procedure is to cure the material in water bath at $74^{\circ} \mathrm{C}$ for 8 hours or longer (long curing cycle). Another satisfactory method is to cure the material in water bath at $74^{\circ} \mathrm{C}$ for 1.5 hours and then at $100^{\circ} \mathrm{C}$ for one hour (short curing cycle) [2].

ProBase Hot" was introduced as a new denture base material which is supposed to set a high standard of quality for the processing properties, accuracy of fit, and stability of shape than that of heat cured denture base materials. This study was conducted to compare the retention of maxillary denture bases with different palatine arch forms constructed from ProBase Hot with those constructed from conventional heat cured acrylic denture resin processed using different curing cycles.

\section{Materials and Methods}

Completely edentulous patients were selected from those attending the Prosthodontic department, Faculty of Dentistry, Mansoura University. One patient had a moderately high U-shaped palatine vault (common arch form), while the other patient had a high V-shaped palatine vault. Their maxillary residual alveolar ridges were free of any obvious ridge undercuts and covered with firm, dense and healthy mucosa. Primary impression of the maxillary arch was made using irreversible hydrocolloid impression material (Cavex CA37, Normal Set. Cavex Holland BV, RW Haarlem, the Netherlands). It was rinsed and immediately poured into plaster to obtain a primary cast. Auto-polymerized spaced acrylic resin (Acrostone, Acrostone dental factory, El-Salam city, Egypt) special tray was fabricated and border molded using green stick compound (Kerr Italian S.r.l., via Passanti 332, I-84018 Scafati, and Salerno, Italy). Secondary impression was taken using zinc oxide eugenol impression material (Cavex CA37, Cavex Holland BV, RW Haarlem, and The Netherlands), exerting slight pressure to the mucosa. It was rinsed, boxed and poured in extra-hard dental stone (Kopo-Rock CKR-35, Kopo-Dental, and ISI-KUANG PANG). A master cast was obtained for each maxillary arch (a master cast with $U$ shaped palatine form and a master cast with V-shaped palatine form). Each master cast was duplicated into twenty-one stone casts using duplicating reversible hydrocolloid.

To obtain standardized maxillary denture bases, the waxed denture base was duplicated using putty form silicone elastomeric impression material (Alphasil Perfect. Muller-Omicron GmbH and Co. KG, D-51789 Linder, Germany) to make an impression for the upper denture base together with its cast, using a large stock tray contoured with base-plate wax. The impression material was sufficient to cover the entire polished surface of the waxed denture base to or beyond the height of the cast inside the tray. The excess material was trimmed to be flushed with the borders of the base of the cast. After setting of the material, the waxed denture base together with its cast was removed, leaving a mold within the impression material. Two escaping holes were prepared at the rear wall of the rubber base impression mold. One of the intact duplicate casts was seated in the mold carefully, in its position outlined during denture base duplication. The cast and the tray containing the mold were tightened together using a rubber band. Molten base-plate wax
(Cavex Set Up, Cavex Holland BV, RW Haarlem, The Netherlands) was poured in the mold cavity from one of the two holes previously prepared at the rear of the impression mold. The other hole was used for the escape of air and excess molten wax. After wax was cooled, the cast, together with the formed wax denture base, was removed from the impression mold. The previous procedure was repeated for all the duplicate casts. Twenty-one standardized denture bases for each tested (U and V- shaped) maxillary arch forms were obtained.

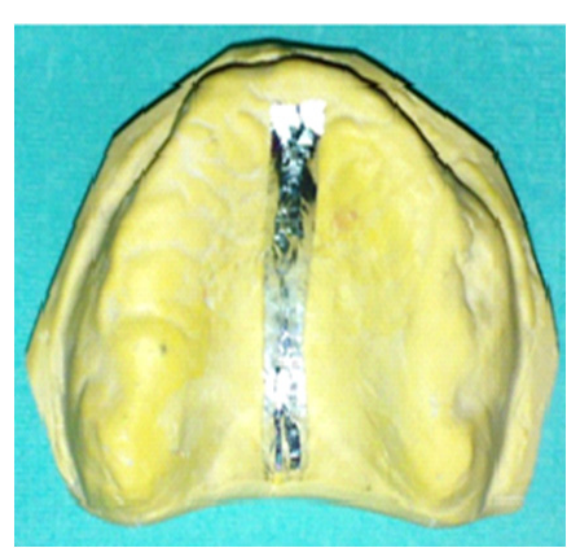

Figure 1: Tin foil strip adaptation at mid-palatal line.

To determine the mid-palatal point (geometrical center). A thin foil strip was adapted to the original master cast on a line drawn from the posterior border of the incisive papilla to the point between the two fovea palatine (Figure 1). The mid-way point was considered as the center of the palate (Figures $2 \& 3$ ). The stone cast was positioned on the analyzing table of the surveyor using a piece of soft compound material jig (Red Cakes, Kerr, Passanti 332, Italy) (Figure 4). The compound jig was used for repositioning the waxed denture base and its stone cast on the surveyor. A point metal tip was secured in the chunk of the surveyor and positioned against the predetermined center on the stone cast. The surveyor was kept in this position (Figure 5). Each waxed denture base and its stone cast was repositioned on the compound jig and its center was marked using the pointed metal tip (Figure 6).

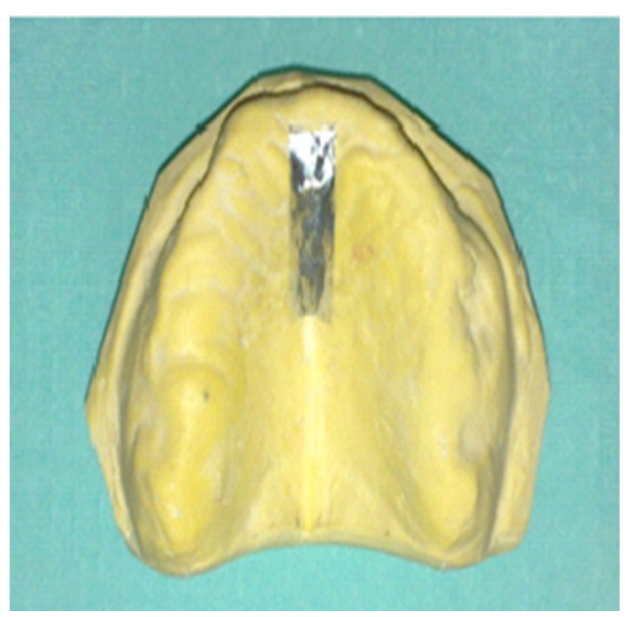

Figure 2: Mid-palatal point location. 


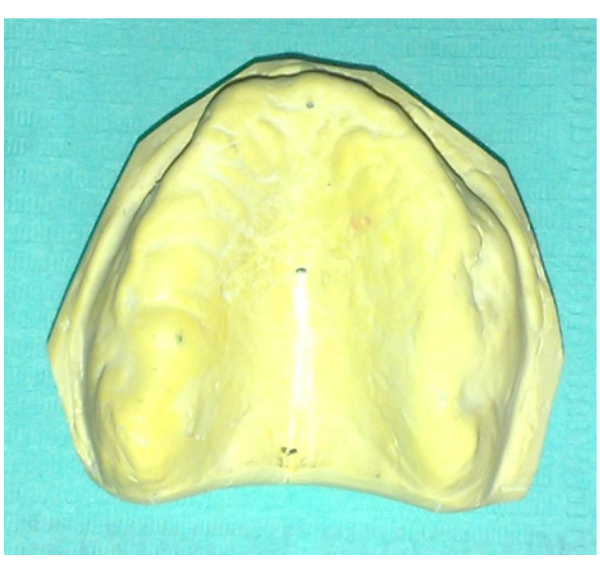

Figure 3: Mid-palatal point marking.

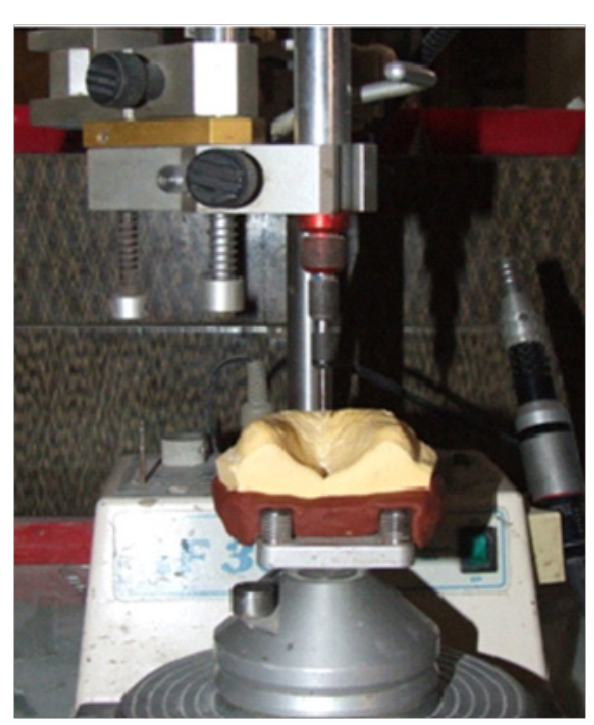

Figure 4: Maxillary master cast positioned on the analyzing table of surveyor using compound jig.

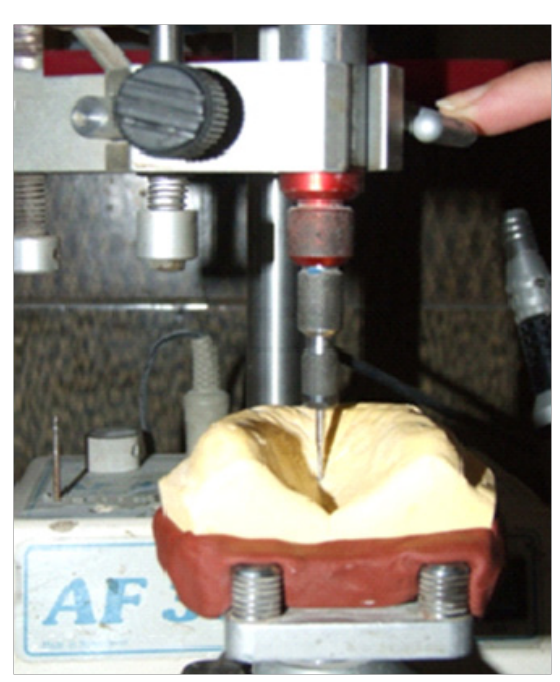

Figure 5: Pointed metal tip secured in the chunk of surveyor and positioned against the predetermined center on the master cast.

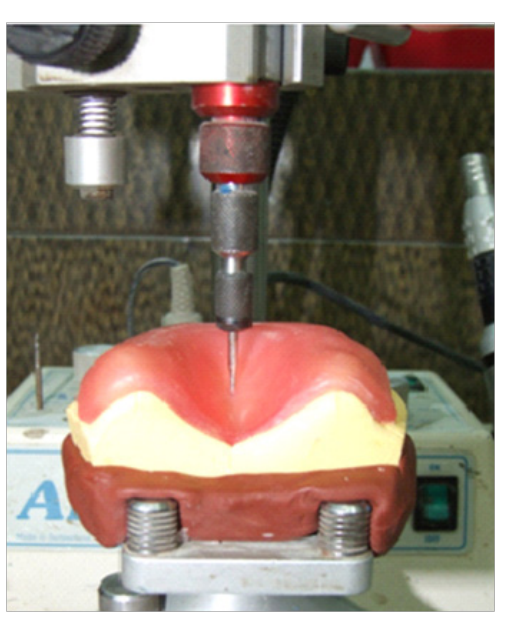

Figure 6: Waxed denture base center marked using pointed metal tip at the same fixed position.

Stainless steel wire loops of the same shape, length and diameter were shaped and each of them was correctly placed at a vertical direction in the marked center of each waxed denture base. The wire loop was used later for dislodging each acrylic denture base from its basal seat inside the patient's mouth to test its retention. Fourteen out of the twenty-one waxed denture bases constructed for each of $\mathrm{U}$ - and V-shaped palatal vault were processed into conventional heat cured acrylic (Acrostone, Acrostone Dental factories, EL-Salam city, Egypt). While the other seven waxed denture bases were processed into ProBase Hot denture bases (ProBase Hot ${ }^{\circledR}$, Ivoclar Vivadent AG., Schaan/ Liechtenstein). The waxed bases were flasked, washed and packed. Seven packed conventional heat cured denture bases were cured in water bath at 74oC for 8 hours (long curing cycle). Seven packed conventional heat cured denture bases were cured in water bath at $74 \mathrm{oC}$ for 1.5 hours and then for $100 \mathrm{oC}$ for 1 hour (short curing cycle). Seven packed Probase Hot denture bases were cured in water bath at $100 \mathrm{oC}$ for 1.5 hour (as recommended by the manufacturer). After curing, the flasks were left to cool to the room temperature and the denture bases were deflasked and finished.

For retention measurement, a digital force meter (Compact Force Gauge, Mecmesim limited, Newton House, Spring Copse, Business Park, Stinfold West Sussex, RH13 OSZ, England) was used to measure the force in grams needed to dislodge the upper denture base from its basal seat. The force meter was able to record the maximum force exerted before the denture was dislodged. It could not dislodge the denture in a vertical direction due to its outer form, so we had to prepare a special design as an aid. A special design was made to allow dislodging force to be applied vertically to the denture base. It was made as follows: Heat-cured acrylic denture base was constructed on the master cast of the lower ridge of each patient. Jaw relation for the patient was recorded using occlusal waxrims. A solid rod with a bearing (WTN Bearing. WTN Corporation, Japan) fitted to its center was constructed. The bearing had a ring fitted around its external surface.

This ring had a groove throughout its central portion which allows a thread to be easily encircled around (Figures 7A and 7B). 
The rod, carrying the bearing with the ring, was attached to the lower wax occlusal rim on both sides, at a higher level than the occlusal plane. The rod was placed perpendicular to the midline of the denture base and the bearing was directly below the loop in the upper denture base when the articulator was opened by an amount resembling moderate mouth opening during measurements. A plaster index was made in the lingual portion of the cast to hold the rod in place. Wax rim was removed, the denture base was cleaned and the rod was fixed to the denture base using self-cure acrylic material (Figure 8). One end of a thread was tied to the loop in the center of the upper denture base, and then the thread was allowed to pass around the groove in the ring, to end up by the other end tied to the hook of the force meter. When the thread was pulled by the end tied to the force meter, it moved with the bearing around the rod pulling the other end in a vertical direction to the upper denture base. A Digital force gauge was used for measurement of the dislodging force vertically to the denture base in grams.

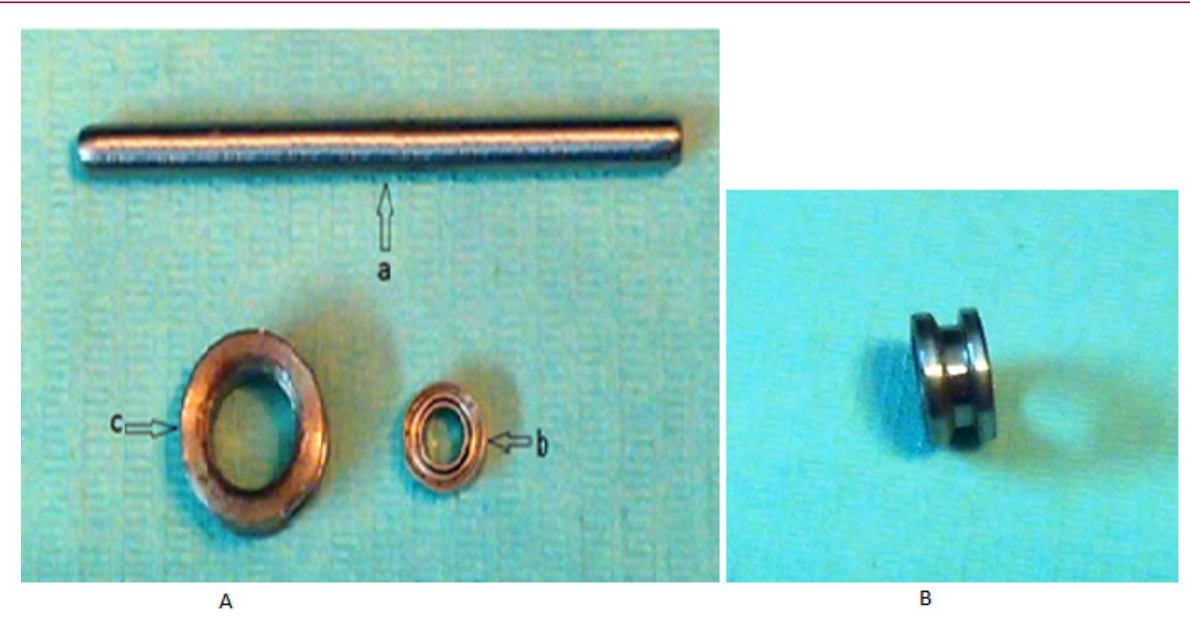

Figure 7: Components of a special design used as an aid for proper maxillary denture base retention measurements. A: (a) solid rod, (b) bearing (size $\left.4^{*} 8\right)$, (c) ring. B: a groove is prepared throughout the center of outer surface of the ring.

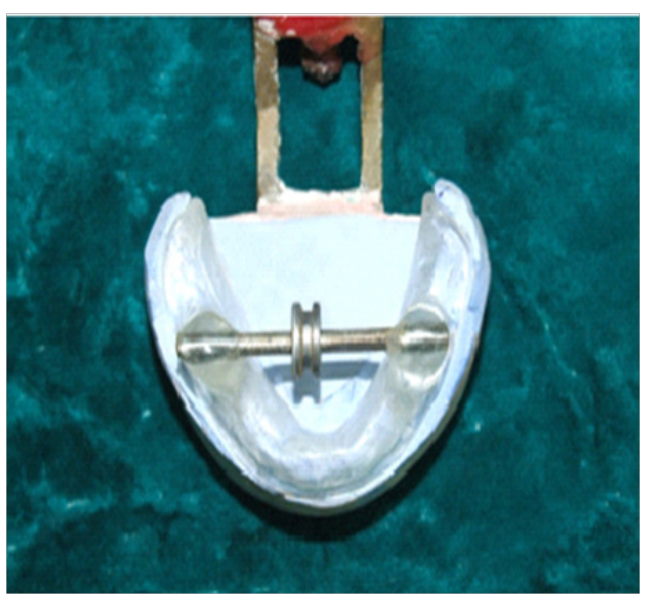

Figure 8: Special design used as an aid for proper maxillary denture base retention measurements.

\section{Statistical Analysis}

The data of this study was analyzed using ANOVA test at the level of significant $5 \%$. When F-test showed a significant difference, Least Significant Difference (LSD) test was used to compare the significant differences between the groups.

\section{Results}

The mean forces in grams used to dislodge the denture bases of both materials out of their corresponding U- and V- shaped maxillary vaults are presented in Table 1. 2- Way ANOVA showed significant difference within the tested groups ( $\mathrm{p} \leq 0.001)$. Regarding the U-shaped palatine arch form, the ProBase Hot denture bases showed significantly higher retention when compared to the long and short curing of the conventional heat-cured denture bases (Acrostone). Also, the long curing of the Acrostone denture bases showed significantly higher retention when compared to the short curing method $(\mathrm{p} \leq 0.05)$.

Table 1: Comparison between ProBase Hot and Acrostone maxillary denture bases regarding mean force (gm) used to dislodge the denture bases out of their corresponding $\mathrm{U}$ and $\mathrm{V}$ shaped maxillary vaults.

\begin{tabular}{|c|c|c|c|}
\hline \multirow{2}{*}{ Arch form } & \multirow{2}{*}{ ProBase Hot } & \multicolumn{2}{|c|}{ Conventional acrylic (Acrostone) } \\
\cline { 3 - 4 } & Long cure & Short cure \\
\hline $\begin{array}{c}\text { U-shaped arch } \\
\text { form }\end{array}$ & $2672.67 \pm 532.2$ & $1479.57 \pm 556.4$ & $1296.29 \pm 242.2$ \\
\hline $\begin{array}{c}\text { V-shaped arch } \\
\text { form }\end{array}$ & $1597.10 \pm 355.1$ & $972.10 \pm 192.2$ & $859.24 \pm 148.9$ \\
\hline F -test & $* * *$ & & \\
\hline LSD = 437.05 & & & \\
\hline
\end{tabular}

\section{*** Highly significant}

Regarding the V-shaped palatine arch form, the ProBase Hot denture bases showed significantly higher retention when compared to the long and short curing of the conventional heat-cured denture bases (Acrostone). Also, the long curing of the Acrostone denture bases showed significantly higher retention when compared to the short curing method ( $p \leq 0.05$ ). The retention of the ProBase 
Hot denture bases in the U-shaped palatine arch form was greater than that of the V-shaped palatine arch form. The retention of the Acrostone denture bases in the U-shaped palatine arch form with both curing methods was greater than that of the V-shaped palatine arch form $(\mathrm{p} \leq 0.05)$.

\section{Discussion}

The magnitude of the acrylic resin dimensional changes, may be influenced by several factors, such as polymerization techniques, where the internal stresses are produced by different coefficients of thermal expansion of gypsum and acrylic resin [6,7], and the base thickness may vary at different sites inside the flask [8,9], altering the denture base adaptation and stability [10]. Consequently, the combination of polymerization shrinkage and strain release decreases the adaptation level of denture base to the supporting tissue, influencing the denture base stability [3]. Besides the factors inherent to the physical properties of acrylic resin, technical procedures and the anatomical conditions of the patient's mouth have been demonstrated previously in the literature [11]. The palatal posterior region, considered to be a critical area in relation to base retention. The processing shrinkage which occurs during polymerization more evident in the posterior palatal region [12].

Patients exhibiting highly tapered, steep (V-shaped) palatal vaults present a special problem. Retention by adhesion is diminished because the palate, having sloping sides, offers only a small area which is horizontal to a vertical displacing force [13]. The study was restricted to the maxillary edentulous arch because locations of the seal areas responsible for retention are constant and don't move during the ordinary functions of the mouth, unlike the mandibular arch [14]. The force applied at the geometrical center of the denture base was considered as the most reliable point to evaluate the denture retention [15]. Determination of the center of the palate and transferring this point to the acrylic denture was an essential procedure to make the dislodging forces equally distributed all over the palatal vault area and ensure balance in testing retention [16]. The magnitude of force required to dislodge the upper denture base from its basal seat inside the oral cavity was assumed to be a measure of denture base retention. The basic concept for testing denture retention is to dislodge the upper denture by a force perpendicular to it. The digital Force meter is a simple device which can apply a gradual force at a definite point in a direction along the longitudinal axis of the extension rod, and measure its amount in grams. The Force meter used in this study can detect force up to 5000 grams. It also provides reproducible data and reduces the risk of injury to the patient $[17,18]$. The only drawback of the used force meter in this study was its shape which makes it impossible to apply a force perpendicular to the center of denture base, thus a special design was made to transfer the force exerted by the force gauge in a perpendicular direction to the denture base.

The specially constructed design for this study consisted of a lower denture base holding a rod with a bearing in its center and a ring around the bearing with a grooved external surface. Using an intraoral design was used for its simplicity and ease of use. The rod, carrying the bearing in its midpoint, was placed parallel to the floor of the mouth and perpendicular to the loop in the upper denture base to allow the bearing to be positioned perpendicular to the loop, thus transferring a vertically applied force. The bearing was used to allow a free motion of the used thread to prevent friction which may alter the results, and a ring with a grooved external surface was fitted around the bearing to allow a room for the thread used to pull the denture base. The rod was placed at level higher than the occlusal plane of the patient to allow a space for the tongue at rest, being kept away from the bearing and thread during measurements and thus allow free movement.

The steps of measuring the denture base retention were carried out in the morning at the same time (between10-12 clock) because the mucosal topography of the denture bearing area is not static during the day Patient's head position was adjusted so that the Frankfort horizontal plane was maintained parallel to the floor. This allows the dislodging forces to be perpendicular to the palatal vault of the maxillary denture. Patient's head was tied to the head rest of the dental chair to prevent sudden forward movement of the head during the test and to minimize the effect of the head movement on the accuracy of the measurements. Each denture base was inserted inside the patient's mouth, kept in its place for five seconds using manual pressure and left in its position for two minutes before applying the dislodging force. This period allowed the settling of the denture base and the sealing effect by functional contact of the surrounding soft structures with the denture base. Every patient was allowed to rest for about twenty minutes before performing the second test. This was to allow recovery of the oral tissues [19].

The results of this study showed a highly significant difference between the tested groups. ProBase Hot denture bases showed maximum retention values compared to Acrostone (both long and short cured). U shaped bases showed better results than V- shaped bases. One of the principal factors contributing to denture retention is the adhesive action of a thin film of saliva between the palate and the fitting surface of the denture. The capillary forces of the salivary film are at a maximum when the distance between the denture surface and the basal seat is at a minimum [20]. This explains how the gap formation between denture base and its corresponding cast negatively affects denture base retention when tested orally. Another reason which affects retention quality is the peripheral seal formed by posterior border of denture base (posterior palatal seal). Gap formation and loss of this seal leads to a decrease in retention of the denture base. In conjunction with correctly extended vestibular borders, the seal of the posterior palatal area will create a partial vacuum under the maxillary denture that is activated only when horizontal or tipping forces are directed against the denture base [21]. Long cured Acrostone denture bases showed slightly better retention than that of the short cured Acrostone bases. The denture bases cured by long-curing cycle exhibited better dimensional stability than that those cured with short curing cycles [22,23].

\section{Conclusion}

Within the limitations of this study, the conclusion could be deduced: 
i. $\quad$ ProBase Hot denture bases showed superior retention values over Acrostone denture bases either long-cured or short-cured.

ii. U-shaped bases showed better results than V- shaped bases in both materials.

\section{References}

1. Anusavice KJ, Shen C, Rawls HR (2013) Phillips, science of dental materials. $12^{\text {th }}(\mathrm{ed})$ St. Louis: Missouri Saunders Elsevier Inc.

2. Power MP, Sakaguchi RL (2006) Craig's restorative dental materials. $12^{\text {th }}$ (ed) St. Louis; Mosby Co. Elsevier Inc pp: 520-531.

3. Takamata T, Arakawa H, Inoue Y, Sagitou S, Kurita K, et al. (1989) Dimensional Accuracy of Acrylic resin denture bases: Literature review. Mutsamoto Shigaku 15: 27-37.

4. Macedo VC, Cotes C, Cabrini RR, Paes-Junior TJA, Carvalho RF, et al. (2014) Influence of Polymerization Technique and Resin Type in Denture Misfit. J Dent App 1(6): 124-128.

5. Laughlin G (2001) A comparison of palatal adaptation in acrylic resin denture bases using conventional and anchored polymerization techniques. J Prosthodont 10(4): 204-211.

6. Thompson VP, William EF, Bailey WG (1979) Dental resins with reduced shrinkage during hardening. J Am Dent Assoc 58(5): 1522-1532.

7. Woelfel JB, Paffenbarger GC, Sweeney WT (1965) Clinical evaluation of complete dentures made of 11 different types of denture base materials. J Am Dent Assoc 70(5): 1170-1188.

8. Wolfaardt JF, Cleaton JP, Fatti P (1986) The influence of processing variables on dimensional changes of heat-cured polymethyl methacrylate. J Prosthet Dent 55: 518-25.

9. Chen JC, Lacefield WR, Castleberry DJ (1988) Effect of denture thickness and curing cycle on the dimensional stability of acrylic resin denture bases. Dent Mat 4(1): 20-24.

10. Jackson AD, Grisius RJ, Fenster RK, Lang BR (1989) Dimensional accuracy of two denture base processing methods. Int J Prosthod 2(5): 421-428.

11. Consani RLX, Domitti SS, Rizzattibarbosa CM, Consani S (2002) Effect of Commercial Acrylic Resins on Dimensional Accuracy of the Maxillary Denture Base. Braz Dent J 13(1): 57-60.
12. Latta GL, Bowles WF, Conkin JE (1990) Three dimensional stability of new denture base resin in the mold processing. J Prosthet Dent 63(6): 654-661.

13. Macgregor AR (1989) Fenn, Liddelow, and Gimson's clinical dental prosthesis, $3^{\text {rd }}(\mathrm{ed})$, Butterworth and Co. (publishers) Ltd pp. 188.

14. Wright CR (2004) Evaluation of factors necessary to develop stability in mandibular dentures. J Prosthet Dent 92(6): 509-518.

15. Colon A, Kotwal K, Mangelsdorff AD (1982) Analysis of the posterior palatal seal and the palatal form as related to the retention of complete dentures. J Prosthet Dent 47(1): 23-27.

16. El-Mahdy MM (2000) Comparison between soft liner and denture adhesive on the acrylic maxillary complete denture retention. Egypt Dent J 46: 853-858.

17. Shawky AM (2010) Comparing the retention of microwave cured versus heat cured acrylic denture. Egy Dent J 56: 511.

18. Niedermeier WHW, Kramer R (1992) Salivary secretion and denture retention. J Prosthet Dent 67: 211-216.

19. Lytle RB (1962) Soft tissue displacement beneath removable partial and complete dentures. J Prosthet Dent 12(1): 34-43.

20. Polyzois GL (1990) Improving the adaptation of denture bases by anchorage to the casts: a comparative study. Quintessence Int 21(3):185-190.

21. Winkler S (1988) Essentials of complete denture Prosthodontics, $2^{\text {nd }}$ (ed) PSG Publishing Co, Inc. Littleton, Massachusettes pp: 107-177.

22. Shankar T, Gowd S, Ahmed ST, Vinod V, Goud MV, et al. (2012) A comparative evaluation of the dimensional accuracy of heat polymerized acrylic resin denture base clamped by the conventional method and by the new-press technique and cured by long curing cycles: An in vitro study. The journal of contemporary dental practice 13(6): 842-849.

23. Takamata T, Setcos JC, Phillips RW, Boone ME (1989) Adaptation of acrylic resin dentures influenced by the activation mode of polymerization. J Am Dent Assoc 119(2): 271-276.

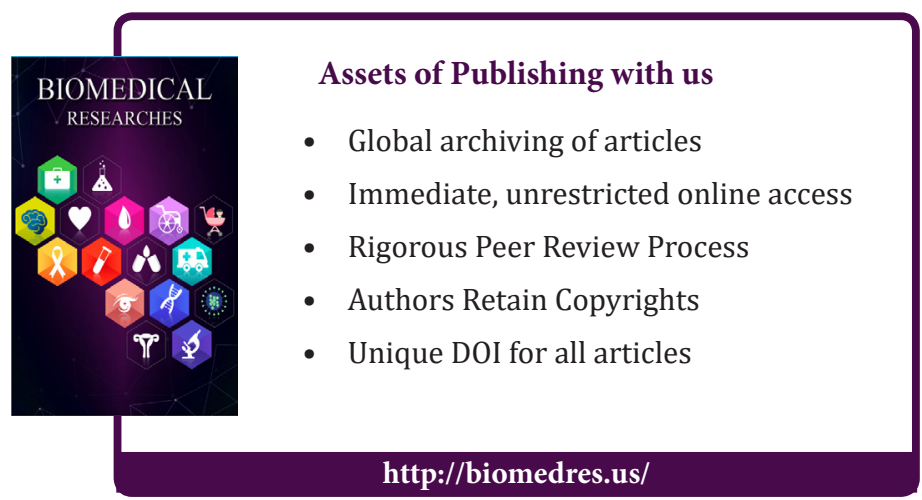

